\title{
Kinetics of corneal leukocytes by intravital multiphoton microscopy
}

\author{
Yashar Seyed-Razavi, ${ }^{,+t, \neq}$ Maria J. Lopez, ${ }^{*,+, \neq}$ Dimosthenis Mantopoulos, ${ }^{\neq, \S}$ Lixin Zheng, ${ }^{\neq, \S}$

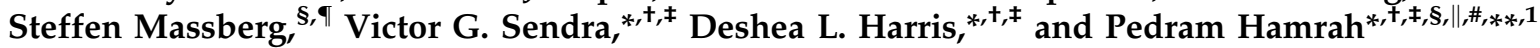 \\ ${ }^{*}$ Center for Translational Ocular Immunology and ${ }^{\dagger}$ Department of Ophthalmology, Tufts Medical Center, Tufts University School of Medicine, \\ and "Sackler School of Graduate Biomedical Sciences, Tufts University Boston, Massachusetts, USA; ${ }^{\ddagger}$ Schepens Eye Research Institute and \\ **Cornea Service, Department of Ophthalmology, Massachusetts Eye and Ear Infirmary, and ${ }^{\S}$ Division of Immunology, Department of \\ Microbiology and Immunobiology, Harvard Medical School, Boston, Massachusetts, USA; ${ }^{\top}$ Department of Cardiology, Ludwig Maximilians \\ Universität, Munich, Germany; and ${ }^{\#}$ Cornea Service, Tufts New England Eye Center, Boston, Massachusetts, USA
}

ABSTRACT: Corneal immune privilege is integral in maintaining the clear avascular window to the foreign world. The presence of distinct populations of corneal leukocytes (CLs) in the normal cornea has been firmly established. However, their precise function and kinetics remain, as of yet, unclear. Through intravital multiphoton microscopy (IV-MPM), allowing the means to accumulate critical spatial and temporal cellular information, we provide details for long-term investigation of CL morphology and kinetics under steady state and following inflammation. Significant alterations in size and morphology of corneal CD11 ${ }^{+}$dendritic cells (DCs) were noted following acute sterile inflammation, including cell volume $\left(4364.4 \pm 489.6 \mathrm{vs} .1787 .6 \pm 111.0 \mu \mathrm{m}^{3}, P<0.001\right)$ and sphericity $(0.82 \pm 0.01 \mathrm{vs} .0 .42 \pm$ $0.02, P<0.001)$ compared with steady state. Furthermore, IV-MPM analyses revealed alterations in both the CD11 $c^{+}$DC and major histocompatibility complex class II (MHC)- $\mathrm{II}^{+}$mature antigen-presenting cell population kinetics during inflammation, including track displacement length (CD11c: $16.57 \pm 1.41$ vs. $4.64 \pm 0.56 \mu \mathrm{m}, P<0.001$; MHC-II: $9.03 \pm$ 0.37 vs. $4.09 \pm 0.39, P<0.001$ ) and velocity (CD11c: $1.91 \pm 0.07 \mu \mathrm{m} / \mathrm{min}$ vs. $1.73 \pm 0.1302 \mu \mathrm{m} / \mathrm{min} ;$ MHC-II: $2.97 \pm 0.07$ vs. $1.62 \pm 0.08, P<0.001)$ compared with steady state. Our results reveal in vivo evidence of sessile CL populations exhibiting dendritic morphology under steady state and increased velocity of spherical leukocytes following inflammation. IV-MPM represents a powerful tool to study leukocytes in corneal diseases in context.-Seyed-Razavi, Y., Lopez, M. J., Mantopoulos, D., Zheng, L., Massberg, S., Sendra, V. G., Harris, D. L., Hamrah, P. Kinetics of corneal leukocytes by intravital multiphoton microscopy. FASEB J. 33, 000-000 (2019). www.fasebj.org

KEY WORDS: antigen-presenting cells $\cdot$ dendritic cells $\cdot$ MHC-II $\cdot$ keratitis $\cdot$ cell morphology

The precise microanatomy of the cornea, along with the lens and clear media of the vitreous, is crucial for the maintenance of vision. The ocular surface is constantly subjected to environmental challenges, including pathogens and allergens, which can result in inflammation and subsequent loss of transparency as a result of corneal scarring. Historically, a purported absence of leukocytes was believed to account for the immune-privileged status of the cornea that was thought of as a passive collagenous tissue (1). Anti-

ABBREVIATIONS: 2D, 2-dimensional; 3D, 3-dimensional; APC, antigenpresenting cell; CL, corneal leukocyte; DC, dendritic cell; eGFP, enhanced green fluorescent protein; eYFP, enhanced yellow fluorescent protein; GFP, green fluorescent protein; IV-MPM, intravital multiphoton microscopy; MHC-II, major histocompatibility complex class II; pDC, plasmacytoid dendritic cell

${ }^{1}$ Correspondence: Department of Ophthalmology, Tufts Medical Center, Tufts University School of Medicine, 800 Washington St., Box 312, Boston, MA 02111, USA. E-mail: pedram.hamrah@tufts.edu

doi: $10.1096 /$ fj.201800684RR

This article includes supplemental data. Please visit $h t t p: / / w w w$.fasebj.org to obtain this information. inflammatory mediators, such as TGF- $\beta$ and FasL (2-4), as well as the absence of major histocompatibility complex (MHC)-II antigens (5), lack of blood (6), and lymphatic vessels (4), contribute to the maintenance of corneal immune privilege and thus, grant the cornea protection from immunologic damage (7-10). The recent discovery of steady-state bone marrow-derived leukocytes in the cornea has subsequently resulted in a paradigm shift in corneal immunology (11, 12). The immune-privileged nature of the cornea is now thought to be an active process, allowing for specific and selective immunologic responses to protect the cornea (13).

The cornea is endowed with distinct populations of corneal leukocytes (CLs) during steady state, which include epithelial and stromal conventional dendritic cells (DCs), stromal macrophages, as well as a putative population of plasmacytoid DCs (pDCs) $(14,15)$. CD45 ${ }^{+} \mathrm{CD} 11 \mathrm{c}^{+}$ DCs, possessing differential expression of CD11b, populate the corneal epithelium and stroma, with mature (MHC$\mathrm{II}^{+} \mathrm{CD} 80^{+} \mathrm{CD} 86^{+}$) and immature $\mathrm{CD} 11 \mathrm{c}^{+} \mathrm{DC}$ residing within the peripheral cornea and universally immature DCs in the central cornea (16-21). In addition, $\mathrm{CD} 45^{+} \mathrm{CD} 11 \mathrm{c}^{-}$ 
$\mathrm{CD} 11 \mathrm{~b}^{+} \mathrm{F} 4 / 80^{+} \mathrm{Iba}-\mathrm{1}^{+}$macrophages are localized throughout the posterior corneal stroma $(19,22-27)$. Furthermore, myeloid-derived CLs, such as DCs and macrophages, express the fractalkine receptor $\left(\mathrm{CX}_{3} \mathrm{CR} 1\right)$ (23). Moreover, a small population of Langerin ${ }^{+}$DCs has also been described in the corneal far peripheral and limbal epithelium, as well as in the central and paracentral corneal stroma (28). The presence of putative $\mathrm{CD} 45^{+} \mathrm{CD} 11 \mathrm{c}^{\mathrm{lo}} \mathrm{B} 220^{+} \mathrm{pDC}$ has been reported within the corneal stroma (29). During acute inflammation, circulating leukocytes, including neutrophils, DCs, and macrophages, enter the cornea from limbal vessels, whereas CLs undergo maturation and increase MHC-II, CD80, and CD86 expression $(14,20)$. How CLs behave and are regulated in the homeostatic cornea and how this tight regulation is lost during inflammation, however, remain unclear. This presents a clear need for the real-time investigation of CL behavior in an intact corneal microenvironment during health and disease.

Intravital multiphoton microscopy (IV-MPM) has allowed the study of leukocyte kinetics and cell-cell communication within solid organs and tissues (30-34). The benefits of a small focal point, greater penetration, and limited phototoxicity of IV-MPM allow for high spatial and temporal resolution analysis of single-cell dynamics in vivo (35-37). Moreover, second harmonic generation from MPM allows for delineation of collagen from surrounding tissue (38), a benefit that has been used in the investigation of unstained corneas (39-41). To date, intravital studies of leukocyte kinetics have been conducted in a number of tissues and organs, including lymph node (42,43), skin (44), adipose tissue (45), bone marrow (46), and the gastrointestinal tract (47). The successful imaging of such tissues is a result of relatively easy exposure, as well as ease of temperature regulation and tissue stabilization. In contrast, whereas the cornea is easily accessible, poor tissue stabilization as a result of nystagmus, ocular pulsation, and breathing artifacts has made intravital imaging of the cornea more difficult. Furthermore, thermal regulation of the avascular cornea is largely reliant on blinking reflex, as it rapidly cools when exposed (48). Nevertheless, the optically clear, avascular, and highly innervated cornea would allow analysis of immune responses in different disease states and would provide a great tissue model for the investigation of angiogenesis, lymph-angiogenesis, and innervation, as well as allowing for dissection of mechanisms of immune privilege.

MPM on explanted corneas has recently been used to elucidate architectural information on epithelial cells, keratocytes, and collagen fibers $(33,39,41,49-52)$, as well as to assess surveillance extension and retraction habitude of DCs (53). The only published article to date that used IV-MPM in investigating leukocyte kinetics in the anterior segment of the eye revealed interactions between lymphatic vessels and adjacent autofluorescent leukocytes, $15 \mathrm{~min}$ following intrastromal injection of the fluorescently conjugated anti-lymphatic vessel endothelial hyaluronic acid receptor 1 antibody in the stroma (54). The paucity of detailed CL kinetics analysis led us to develop a novel IV-MPM model for fluorescent transgenic mice, allowing for leukocyte visualization and analysis throughout the entire cornea, while maintaining long-term, tight temperature regulation and tissue stability. With the use of this model, we performed novel, 3-dimensional (3D), morphologic, and kinetic analyses of the CL during homeostasis and following acute inflammation.

Herein, we provide the necessary conditions required for long-term, noninvasive corneal IV-MPM and detail 3D morphologic analyses of $\mathrm{CD} 11 \mathrm{c}^{+} \mathrm{DC}$ and $\mathrm{MHC}-\mathrm{II}^{+}$mature antigen-presenting cells (APCs), including volume and sphericity during steady state and following acute inflammation, which to our knowledge, has not been previously reported in the literature. Furthermore, we highlight CLs to be sessile under steady-state conditions, with acute inflammation resulting in an increase in their displacement and kinetics.

\section{MATERIALS AND METHODS}

\section{Animals}

CD11c-enhanced yellow fluorescent protein (eYFP, kindly provided by Dr. Michel C. Nussenzweig, The Rockefeller University, New York, NY, USA) (55), CD11c-enhanced green fluorescent protein (eGFP) (56), MHC class II-eGFP (57), and CX $\mathrm{C}_{3}$ CR1-eGFP (58) transgenic mice (all C57BL/6 background), aged 6-12 wk, carrying a fluorescent transgene under the control of the murine CD11c or MHC-II promoter or with GFP replacing the $\mathrm{CX}_{3} \mathrm{CR} 1$ gene, were bred in house to homozygotes to better visualize CL populations in the present study. Wild-type C57BL/6 mice, purchased from The Jackson Laboratory (Bar Harbor, ME, USA), were also used for corneal flat-mount staining. Mice were housed at Harvard Medical School, Schepens Eye Research Institute, and Tufts Medical Center animal vivariums, and all animals were treated in compliance with the guidelines set forth by the Association for Research in Vision and Ophthalmology and Ophthalmology Statement for the Use of Animals in Ophthalmic and Vision Research. All animal experiments were reviewed and approved by the Institutional Animal Care and Use Committee at each center.

\section{Murine model of acute inflammation with thermal cautery burn}

Mice were initially anesthetized with an intraperitoneal injections of ketamine hydrochloride $(100 \mathrm{mg} / \mathrm{kg})$ and xylazine (20 mg/ kg). Under a dissecting microscope, topical anesthetic drops $(0.5 \%$ Proparacaine hydrochloride ophthalmic solution; Akorn, Lake Forest, IL, USA) were applied to the ocular surface, and 5 light burns were induced to the central $50 \%$ of the cornea using the tip of a hand-held thermal cautery (Aaron Medical Industries, St. Petersburg, FL, USA), as previously described (20). Antibiotic ointment (Vetropolycin bacitracin-neomycin-polymyxin ophthalmic ointment; Dechra, Overland Park, KS, USA) was applied to the cornea and subcutaneous injection of buprenorphine $(0.05-0.1 \mathrm{mg} / \mathrm{kg})$ administered immediately following cautery and repeated every $12 \mathrm{~h}$ for the next $72 \mathrm{~h}$. Leukocyte distribution and kinetics were captured at 2, 5, and $7 \mathrm{~d}$ after corneal thermal burns with IV-MPM, as described below.

\section{Corneal IV-MPM}

\section{Anesthesia and body temperature regulation}

Animals were anesthetized with an intraperitoneal injection of ketamine $(100 \mathrm{mg} / \mathrm{kg}) / x y l a z i n e ~(20 \mathrm{mg} / \mathrm{kg}) /$ acepromazine $(3 \mathrm{mg} / \mathrm{kg}$ ) mixture, resulting in up to $70 \mathrm{~min}$ of deep anesthesia. Vital signs, including pulse, respiration, and oxygen saturation, 
were monitored with the MouseOx system (Starr Life Sciences, Oakmont, PA, USA) throughout all procedures. Mice were placed on a custom and tiltable stereotactic stage (Harvard's National Eye Institute (NEI) Vision Core, Machine Shop Module; Fig. 1A). To prevent mouse hypothermia, the body temperature was maintained at $35-37^{\circ} \mathrm{C}$ using disposable hand warmers (HotHands; HeatMax/Kobayashi, Dalton, GA, USA) and foil cover (Fig. $1 B$ ) or a heating blanket (Harvard Instruments, Holliston, MA, USA). The proper depth of anesthesia was assessed every 30-60 $\mathrm{min}$ and supplemented as required, with alternating doses of ketamine alone $(100 \mathrm{mg} / \mathrm{kg})$ or ketamine/xylazine/ acepromazine mixture at the previously mentioned doses.

\section{Corneal preparation for intravital multiphoton microscopy}

Following induction of deep anesthesia, topical Proparacaine $(0.5 \%)$ and Genteal ophthalmic lubricant gel (Alcon, Fort Worth, TX, USA) were applied to each eye to prevent pain and corneal desiccation during the IV-MPM preparation, respectively. To reduce autofluorescent signals from the periorbital fur, the fur was completely removed with an electric shaver and Nair hairremoval cream (Church \& Dwight, Princeton, NJ, USA) applied for $2 \mathrm{~min}$, applied under a dissection microscope to ensure no contact with the eye to prevent irritation. Next, a 5-0 nonabsorbable silk suture (Surgical Specialties Corp., Reading, PA, USA) was placed around the eye to prevent eye closure, blinking, and nystagmus, while allowing the normal flow of blood to the eye. To minimize or prevent breathing and motility artifacts, the mouse head was secured by the nose and jawlines in our custom stereotactic stage with a tiltable bed, allowing imaging of both eyes of the animal accordingly (Fig. $1 A, B$ ). High vacuum grease (Dow Corning, Midland, MI, USA) was applied onto the bare skin surrounding the eye and a plastic ring, prepared from an Eppendorf tube, was placed on the grease to form a sealed chamber around the exposed portion of the eye (Fig. 1B, C). Once Genteal gel was added to the well, a thin $(0.18 \mathrm{~mm})$ coverslip with tubing, allowing for circulating heated water, was placed onto the even surface of the plastic ring so that it maintained constant contact with the cornea to allow for heat dissipation and to increase the area of imaging given corneal asphericity (Fig. 1B, C).

\section{Corneal temperature regulation}

The ocular surface temperature was regulated with a step-down system of tubing with a Diba polytetrafluoroethylene fittings union connector/reducer (Cole Palmer, Vernon Hills, IL, USA) to create pressure, ending with polyethylene tubing (PE \#20; BD Intramedic, Sparks, MD, USA), which was formed into a ring placed on the glass coverslip (Fig. 1B,C). Hot water was circulated using a Masterflex L/S peristaltic pump (Cole Parmer, Vernon Hills, IL, USA) with a flow rate of $10 \mathrm{ml} / \mathrm{min}$ through the tubing and coverglass assembly placed on top of the cornea with additional Genteal gel added within the chamber. Corneal temperature was monitored throughout imaging with a dual-input digital thermometer (Omega Engineering, Stamford, CT, USA) placed on the cornea away from the imaging area. The water temperature and flow rate settings are based on the distance between water bath and imaging setup and adjusted as required to maintain a temperature range within $2^{\circ} \mathrm{C}$ of the physiologic corneal temperature $\left(34^{\circ} \mathrm{C}\right)(59,60)$ inside the sealed chamber throughout imaging $\left(33-35^{\circ} \mathrm{C}\right.$; Fig. $\left.1 B-D\right)$. Outside of this range, CL movement is not noted.

\section{Intravital multiphoton imaging of corneal leukocyte populations}

IV-MPM was performed with an Ultima Multiphoton Microscope System (Bruker, Fitchburg, WI, USA) equipped with 2 MaiTai Ti/Sapphire DeepSee lasers (Newport Spectra-Physics, Irvine, CA, USA) for simultaneous coaxial illumination at 850and 900-nm wavelengths to achieve 2-photon excitation and second harmonic generation. Photomultiplier tube gains for fluorescence signal and second harmonic generation and laser power were initially set to 787 and 135 , respectively, with adjustments made to these values as required. A $\times 201.0$ numerical aperture (XLUMPLFLN; Olympus, Tokyo, Japan) waterimmersion objective was used to capture $512 \times 512$ resolution with 2-fold line averaging, with a total depth of $120 \mu \mathrm{m}$, with 1- or $3-\mu \mathrm{m}$ optical section slices, to investigate cellular details in high magnification and cellular kinetics, respectively. Scans were taken every 30-60 s over a period ranging from $30 \mathrm{~min}$ to $>1 \mathrm{~h}$.

\section{Flat-mount immunostaining and confocal imaging of the cornea}

The corneas of steady-state and cautery-inflamed wild-type C57BL/ 6 mice were excised, washed in PBS, and fixed in chilled acetone for $15 \mathrm{~min}$ before staining. Following 3 washes to remove residual acetone, the corneas were incubated with Fc block
A
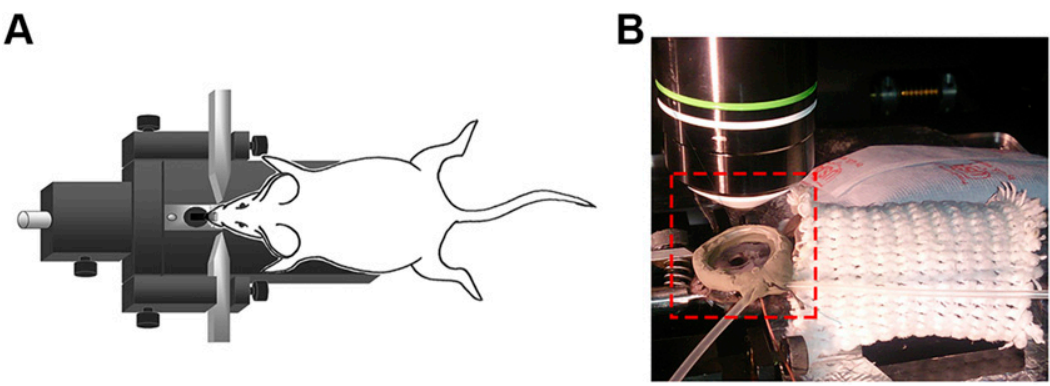

C
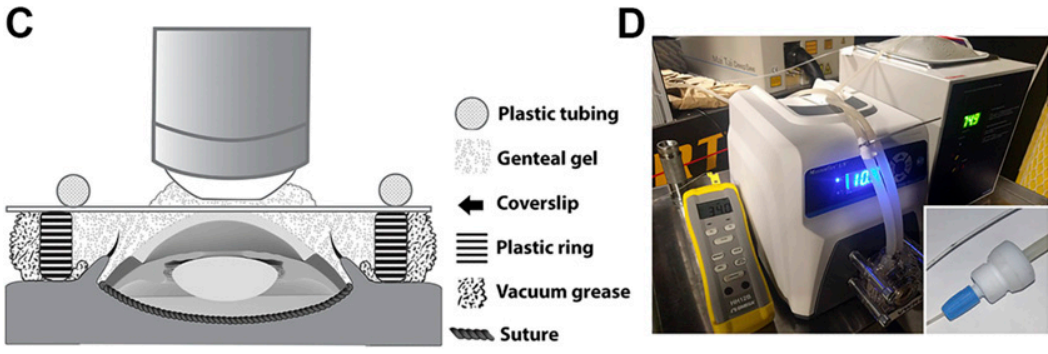

Figure 1. IV-MPM setup. A) A custom-made tiltable stereotactic stage was used to secure the mouse and allow imaging of the eye. $B$ ) Contact between the cornea and a coverslip heated with circulating water allowed regulation of ocular surface temperature by altering the temperature of the chamber formed using a plastic ring and sealed with vacuum grease. C) Schematic highlighting a side view of all of the components of the chamber. $D$ ) The temperature and flow rate of the water were altered as needed throughout imaging to maintain an ocular surface temperature of $34^{\circ} \mathrm{C}$ (inset: step-down connector/reducer). 
(anti-mouse CD16/32, clone 2.4G2, dilution 1:100; BioXCell, West Lebanon, NH, USA) in 3\% bovine serum albumin at room temperature for $30 \mathrm{~min}$ to limit nonspecific antibody binding. The corneas were then stained with conjugated anti-mouse CD11c (HL3; BD Biosciences, San Jose, CA, USA) and MHC-II (I-A/I-E, clone M5/114.15.2; BioLegend, San Diego, CA, USA) overnight at $4^{\circ} \mathrm{C}$. Following 3 washes with PBS, flat mounts were mounted on a slide with Vectashield mounting medium (with DAPI; Vector Laboratories, Burlingame, CA, USA) and imaged with an SP8 confocal microscope (Leica Microsystems, Wetzlar, Germany), equipped with a 20 times 0.9 numerical aperture multi-immersion objective. $Z$ stacks were acquired with $2-\mu \mathrm{m}$ increments and transferred to Imaris (Bitplane, Zurich, Switzerland) software for further analysis.

\section{Image analysis and processing}

\section{Cell morphologic analysis}

Two- and 3-dimensional (2- and 3D, respectively) measurements of cell morphology were calculated using Imaris (Bitplane). The measurement of the farthest distance between opposing points of a cell was taken as a 2D indication of cell size (Measurement Points function, Imaris; Supplemental Fig. S1 $A, B)$. Analysis of cell 3D parameters, including cell-surface area $\left(\mu \mathrm{m}^{2}\right)$, volume $\left(\mu \mathrm{m}^{3}\right)$, and sphericity (range $0-1$, with a score of 1 indicative of a sphere) was obtained after creating a surface object for each stained or transgenic endogenous fluorescent leukocyte population (CD11c, $\mathrm{CX}_{3} \mathrm{CR} 1$, and MHC-II positive) using the surface tool within Imaris software (Supplemental Fig. S1C). Finally, images were processed and collated using Adobe Photoshop CC 2015 (Adobe Systems Europe, London, United Kingdom).

\section{Cell kinetics and motility analysis}

Image stacks were imported and analyzed with Volocity (PerkinElmer, Waltham, MA, USA) or Imaris (Bitplane) imaging softwares. Image stacks were converted into $4 \mathrm{D}$ movies, and semiautomated tracking of cell motility was performed, as previously described $(43,61)$. In brief, the $x y z$ positions of the cell bodies were tracked, using the 3D rendering and cell-tracking functions of these programs over time, manually confirmed at each frame, and minor drift compensation was performed. Furthermore, to optimize cell tracking, baseline subtraction thresholding was performed on movies using a $139-\mu \mathrm{m}$ filter width to reduce nonspecific background fluorescence signal. To quantify leukocyte kinetics, the center point of each cell at each time point was determined and tracked over time to determine the track velocity (average velocity of a cell over length of imaging; $\mu \mathrm{m} / \mathrm{min}$ ), 3D instantaneous velocity (velocity of a cell between 2 consecutive frames), total track length (total track distance of a cell in micrometers), and displacement length (distance from the first position of a cell in the track to the last as a straight line in micrometers), and meandering index (total displacement distance/total migration path length of a cell) was calculated for each cell, as previously described (62). The meandering index provides a measure of the deviation from a straight line of a migratory cell (a value of 1 indicating the track is a straight line). For kinetic analysis, each point represents an individual cell. $3 \mathrm{D}$ Instantaneous velocity provides a measure of altered velocity of a cell from one frame to another within a time series. Static cells with a displacement length $<10 \mu \mathrm{m}$ after acute thermal burn induced inflammation were excluded from the analysis of a meandering index. As CLs are sessile (exhibiting sampling centroid movement without displacement) under steadystate conditions, the steady-state data were also excluded from meandering index analysis.

\section{Flow cytometry}

Cautery-inflamed corneas of C57BL/6 wild-type and CD11cGFP mice were harvested, cut into pieces, and subjected to enzymatic digestion of $60 \mathrm{~min}$ at $37^{\circ} \mathrm{C}$ in $2 \mathrm{mg} / \mathrm{ml}$ collagenase $\mathrm{D}$ (Roche, Indianapolis, IN, USA) and $2 \mathrm{mg} / \mathrm{ml}$ DNAse I (MilliporeSigma, Burlington, MA, USA) in DMEM. Following digestion, the enzymatic digestion stopped with $10 \%$ fetal calf serum in DMEM, and samples were strained using a $70-\mu \mathrm{m}$ nylon mesh to yield single-cell suspension and blocked with $1 \%$ anti-CD16/CD32 FcR mAb (Bio X Cell, West Lebanon, NH, USA) at room temperature for $20 \mathrm{~min}$. Next, corneal single-cell suspensions were labeled with fluorophore-conjugated antibodies against CD45 (30-F11; BioLegend), CD11c (HL3; BD Biosciences), 33D1 (DCIR2; BioLegend), CD19 (6D5; BioLegend), B220 (RA3-6B2; BioLegend), PDCA-1 (927; BioLegend), CD11b (M1/70; BioLegend), F4/80 (BM8; BioLegend), $\mathrm{CX}_{3} \mathrm{CR} 1$ (SA011F11; BioLegend), and MHC-II (I-A/I-E, M5/114.15.2; BioLegend) or appropriate conjugated isotype controls for 60 min at room temperature. Following a wash, samples underwent flow cytometric analysis using a BD LSR II flow cytometer (BD Biosciences) and acquired data analyzed by FlowJo v.10 (Ashland, OR, USA). Debris, dead cells, and doublets were excluded using forward and side scatters and corneal DCs gated on CD45 and CD11c and further analyzed.

\section{Statistical analysis}

Results are presented as means \pm SEM. Three or more time series from different experiments were analyzed and statistical significance determined for each time series by either Student's $t$ test or 1-way ANOVA (Prism; GraphPad Software, La Jolla, CA, USA). A Kolmogorov-Smirnov test was run to assess data distribution. Differences between experimental and control groups were considered significant when $P<0.05$.

\section{RESULTS}

\section{Intravital multiphoton microscopy}

The requirements of careful monitoring of anesthesia, precise temperature regulation, as well as tissue and image stability have resulted in minimal use of IV-MPM for immunoimaging of CLs. Thus, to study the in vivo kinetics and dynamics of cellular movement and interactions of leukocytes in the murine cornea, we designed a custom tiltable stereotactic stage (Fig. 1A, B) to analyze the distribution and migratory kinetics of local steady-state and infiltrating CLs. To analyze CL kinetics, the ocular surface of steady state and inflamed transgenic mice was imaged over time. Our dual-laser system permitted simultaneous imaging of the ocular surface of endogenously fluorescent transgenic mice (green), dextran signal indicative of the tear film layer (red), as well as second harmonic generation revealing the corneal stroma (blue; Supplemental Videos S1 and S2). In vivo analysis of CLs revealed APCs distributed within the epithelium in both en face transverse (Supplemental Video S1) and oblique (Supplemental Video S2) images of the cornea (the corneal epithelium is the area between the dextran-stained tear film and corneal stroma), as well as throughout the corneal stroma (Supplemental Videos S1-3). The analysis of corneal flat mounts revealed a similar distribution of APCs throughout the 
cornea (Supplemental Fig. S2A, B). Whereas 3 transgenic mice strains were used in this study, we placed focus more on CD11c and MHC-II transgenic mice to delineate better morphologic and kinetic alterations within $\mathrm{DC}\left(\mathrm{CD} 11 \mathrm{c}^{+}\right)$ and mature APC (MHC-II $)$ CL populations in an acute inflammation setting compared with steady state. The phenotype of CD11 ${ }^{\text {GFP }}$ was confirmed to align with DCs via flow cytometry (Supplemental Fig. S2).

\section{Analysis of morphologic parameters}

\section{Corneal intravital multiphoton microscopy during steady state}

Analysis of steady-state CLs revealed a spread in cell size among CD11c-, CX ${ }_{3}$ CR1-, and MHC-II-positive cells. With the second harmonic signal signifying the corneal stroma, CLs distributed through the cornea ranged from cells residing in the anterior stroma/corneal epithelium (Supplemental Fig. S3 $A, B, D$ ) presenting dendrites (arrows) to cells deeper in the corneal stroma (Supplemental Fig. S3A, C) presenting minimal to no observable dendrites (arrowheads). Furthermore, the high spatial resolution of the MPM allowed the imaging of fine processes of DCs with soma localized sub-basal of the corneal epithelium and extending processes into the corneal epithelium (Supplemental Fig. S3D, inset: orthogonal view with corneal stroma rendered for clarity). Analysis of CL density within the steady-state corneas of CD11c, $\mathrm{CX}_{3} \mathrm{CR} 1$, and MHC-II transgenic mice yielded values of $100.0 \pm 26.1 \mathrm{cells} / \mathrm{mm}^{2}$, $90.7 \pm 11.3$ cells $/ \mathrm{mm}^{2}$, and $100.0 \pm 10.5$ cells $/ \mathrm{mm}^{2}$, respectively.

To gain a better understanding of whether steady-state $\mathrm{CD}_{11 \mathrm{c}^{+}}$and MHC-II ${ }^{+} \mathrm{APC}$ have morphologic differences, we analyzed and compared CLs from CD11c, $\mathrm{CX}_{3} \mathrm{CR} 1$, and MHC-II ${ }^{\mathrm{eGFP}}$ transgenic mouse models. No difference was noted among the groups (1-way ANOVA with Tukey's post hoc comparison, $P=0.33$ ), with $\mathrm{CD} 11 \mathrm{c}^{+}$ cells having a 2D size of $35.4 \pm 3.3 \mu \mathrm{m}, \mathrm{CX}_{3} \mathrm{CR} 1^{+}$cells having a size of $31.2 \pm 1.3 \mu \mathrm{m}$, and $\mathrm{MHC}-\mathrm{II}^{+}$cells having a size of $34.1 \pm 1.2 \mu \mathrm{m}$ (Supplemental Fig. S3E). After separate analysis of DCs and mature APCs, we found that no significant difference in the cell-surface area was noted among different endogenously fluorescent APCs (CD11 ${ }^{+}$ cells: $3294.4 \pm 345.9 \mu \mathrm{m}^{2}, \mathrm{CX}_{3} \mathrm{CR} 1^{+}$cells: $2793.3 \pm 222.5 \mu \mathrm{m}^{2}$, and MHC-II ${ }^{+}$cells: $3093.0 \pm 141.3 \mu \mathrm{m}^{2} ; P=0.82$; Supplemental Fig. S3F). Interestingly, analysis of 3D volume and 3D sphericity of CLs revealed differences under steady state. CD11c ${ }^{+}$cells had a volume of $4364.4 \pm$ $489.6 \mu \mathrm{m}^{3}$ compared with $\mathrm{CX}_{3} \mathrm{CR} 1^{+}$cells with a volume of $6801.3 \pm 648.2 \mu \mathrm{m}^{3}(P<0.05)$ and MHC-II ${ }^{+}$cells with a volume of $9040.12 \pm 489.1 \mu \mathrm{m}^{3}$ (Supplemental Fig. S3G; $P<0.0001)$. Mean CD11 ${ }^{+}$cell sphericity was $0.43 \pm 0.02$, whereas $\mathrm{CX}_{3} \mathrm{CR}^{+}$and $\mathrm{MHC}-\mathrm{II}^{+}$cells were $0.61 \pm 0.02$ and $0.69 \pm 0.01$, respectively (Supplemental Fig. S3H; $P<$ $0.0001)$. Taken together, our results indicate that $2 \mathrm{D}$ cell size and 3D surface area are not a good measure to discern cell morphologic differences, whereas 3D cell morphologic analyses of cell volume and sphericity are able to differentiate between CLs and quantify the fact that steady-state $\mathrm{CD}_{11 \mathrm{c}^{+}} \mathrm{DCs}$ have a more dendritiform morphology (small soma and fine processes) compared with the more spherical MHC-II ${ }^{+}$APCs. The cell morphology of $\mathrm{CX}_{3} \mathrm{CR}^{+}$ cells aligns them between DCs and mature APCs, as both epithelial DCs and stromal APCs have been shown to express $\mathrm{CX}_{3} \mathrm{CR} 1(23,27)$.

\section{Corneal intravital multiphoton microscopy during inflammation}

We next sought to analyze morphologic differences of CL subpopulations following acute inflammation, in vivo. We found a significant increase in $\mathrm{CD} 11 \mathrm{c}^{+}$leukocyte density (Fig. $2 A, D ; 322.2 \pm 30.3$ cells $/ \mathrm{mm}^{2}$ vs. $100.0 \pm 26.2$ cells / $\mathrm{mm}^{2} ; P<0.001$ ), $\mathrm{CX}_{3} \mathrm{CR}^{+}$leukocyte density (Fig. $2 B, D$; $817.8 \pm 168.2$ cells $/ \mathrm{mm}^{2}$ vs. $90.8 \pm 11.3$ cells $/ \mathrm{mm}^{2} ; P=$ 0.001), and MHC-II ${ }^{+}$APC density (Fig. 2C, D; 622.2 \pm 104.6 cells $/ \mathrm{mm}^{2}$ vs. $100.0 \pm 10.5$ cells $\left./ \mathrm{mm}^{2} ; P<0.001\right)$ into the cornea, 2-5 d following acute inflammation, compared with respective steady-state controls (Fig. $2 A-D$ ). Oblique sections of the cornea with IV-MPM revealed this increased cell density to be throughout the entire cornea (Fig. $2 B$, inset). As the majority of CLs exhibited a spherical phenotype following inflammation (Fig. $2 A, C$ ), typically seen in migratory cells (63), we sought to quantify such a morphologic shift from the typical morphology noted during steady state (Fig. 2E). 2D Cell size analysis revealed a significant change in all CL subsets, with the average cell size decreasing for CD11 $\mathrm{c}^{+} \mathrm{DCs}(21.8 \pm 0.7 \mu \mathrm{m}$ compared with steady state $35.4 \pm 3.3 \mu \mathrm{m} ; P<0.001), \mathrm{CX}_{3} \mathrm{CR} 1^{+}$ (26.1 $\pm 0.5 \mu \mathrm{m}$ compared with steady state $31.2 \pm 1.3 \mu \mathrm{m}$; $P<0.001)$, and MHC-II ${ }^{+}$APCs $(20.1 \pm 0.5 \mu \mathrm{m}$ compared with steady state $34.1 \pm 1.2 \mu \mathrm{m} ; P<0.001$; Fig. $2 F$ ).

We next investigated 3D morphologic changes among the different leukocyte subtypes during inflammation compared with steady state. Analysis of cell-surface area revealed $\mathrm{CD}_{11 \mathrm{c}^{+}}$DCs to possess an almost 4 -fold decreased surface area compared with steady state $(845.0 \pm$ 38.4 vs. $\left.3294.4 \pm 345.9 \mu \mathrm{m}^{2} ; P<0.001\right)$, MHC- $-\mathrm{II}^{+}$APCs showing a 2-fold decrease $(1370.7 \pm 41.1$ vs. $3093.0 \pm$ $\left.141.3 \mu \mathrm{m}^{2} ; P<0.001\right)$, whereas $\mathrm{CX}_{3} \mathrm{CR} 1^{+}$leukocyte cellsurface area decrease the least $(2098.2 \pm 77.9$ vs. $2793.3 \pm$ $222.5 \mu \mathrm{m}^{2} ; P<0.05 ;$ Fig. $2 F$ ). Analysis of 3D cell volume revealed similar results between inflamed state and steady state, with a 2.5 -fold decrease in volume of CD11 $\mathrm{c}^{+}$ DCs during inflammation (1787.6 \pm 111.0 vs. $4364.4 \pm$ $\left.489.6 \mu^{3} ; P<0.001\right)$, as well as MHC-II ${ }^{+}$mature APCs having a 2.5 -fold change $(3626.6 \pm 145.1$ vs. $9040.1 \pm$ $\left.489.1 \mu^{3} ; P<0.001\right)$, whereas $C X_{3} C R 1^{+}$leukocytes had a 1.5-fold decrease in their surface area $(4055.6 \pm 197.4 \mathrm{vs}$. $6801.3 \pm 648.2 \mu \mathrm{m}^{3}$; Fig. $2 G$ ). Cell-sphericity analysis revealed a significant increase in sphericity during inflammation for CD11c ${ }^{+}$DCs $(0.82 \pm 0.01$ vs. $0.42 \pm 0.02)$ and $\mathrm{MHC}-\mathrm{II}^{+}$mature APCs $(0.79 \pm 0.00$ vs. $0.69 \pm 0.01)$ when compared with steady-state measurements $(P<$ 0.001 ; Fig. $2 H)$. The most pronounced change in sphericity in CD11 $\mathrm{c}^{+}$DCs (2-fold) confirms the observation of DCs adopting a more spherical shape (having a high sphericity value) in inflammation compared with the normal elongated dendritiform shape that they exhibit under steady-state conditions (Supplemental Fig. 3A, $D$ compared with Fig. $2 A$ ). $\mathrm{CX}_{3} \mathrm{CR} 1^{+}$leukocyte sphericity 
Figure 2. Investigation of $\mathrm{CL}$ populations following acute inflammation. $A-C)$ Representative IV-MPM images of $\mathrm{CD}_{11 c^{+}}(A), \mathrm{CX}_{3} \mathrm{CR}^{+}$ $(B)$ (inset: transverse section image), and MHC- $\mathrm{II}^{+}$CLs $(C)$ (green) of transgenic mice following thermal cautery injury. Original scale bars, $100 \mu \mathrm{m} . D$ ) Cell density increased in all leukocyte populations following inflammation. $E)$ The morphologic shift from the typical morphology noted during steady state in CD11c and MHC-II leukocytes. $F$ ) 2D Cell size quantification of CD11c ${ }^{+}(\mathrm{d} 5), \mathrm{CX}_{3} \mathrm{CR}^{+}(\mathrm{d} 2)$, and $\mathrm{MHC}_{-} \mathrm{II}^{+}$(d 5) leukocytes following thermal cautery compared with steady state (SS). $G-I)$ 3D Morphologic analyses of leukocyte populations following acute thermal burn injury including cell-surface area $(G)$, volume $(H)$, and sphericity $(I)$ of CD11c (first column), $\mathrm{CX}_{3} \mathrm{CR} 1$ (second column), and MHC-II (third column) transgenic corneas. NS, not significant. Results are presented as means \pm SEM, Student's $t$ test. $* P<0.05, * * P<0.01, * * * P<0.001$.
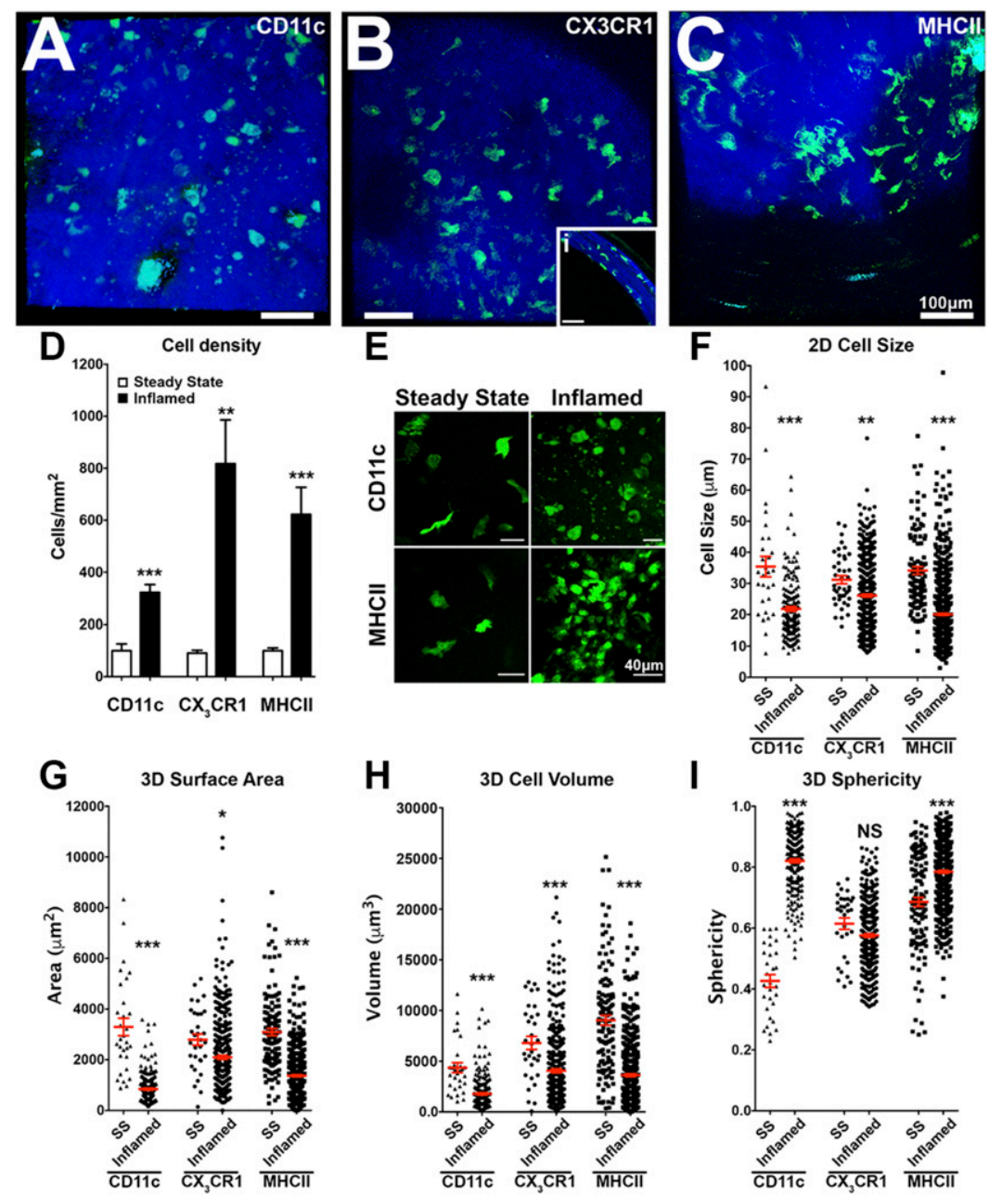

was not significantly changed following inflammation (0.58 \pm 0.01 vs. $0.61 \pm 0.02, P=0.0532)$ when compared with steady state (Fig. $2 H$ ). Taken together, our data demonstrate that inflammation results in increased CL density, as well as alters cell morphology, the most pronounced change in morphology noted within the $\mathrm{CD} 11 \mathrm{c}^{+} \mathrm{DC}$ s following corneal inflammation.

\section{Corneal ex-vivo confocal microscopy analysis}

To confirm that CLs are morphologicically altered following inflammation, we performed immunofluorescence staining of fixed corneas with antibodies against CD11c and MHC-II and performed the same morphologic analysis on CD11c ${ }^{+}$and MHC-II ${ }^{+}$CLs (Supplemental Fig. S4). 2D Cell size of $\mathrm{CD}_{11 \mathrm{c}^{+}}$and $\mathrm{MHC}-\mathrm{II}^{+}$significantly decreases following inflammation (CD11c: $26.0 \pm 0.9$ with a median of 24.5-19.3 $\pm 0.5 \mu \mathrm{m}$ and a median of $17.4 \mu \mathrm{m}$, $P<0.001$; MHC-II: $33.8 \pm 1.0$ with a median of 30.8-20.5 \pm $0.4 \mu \mathrm{m}$ and a median of $18.0 \mu \mathrm{m}, P<0.001$; Supplemental Fig. S4E). We next performed 3D analysis of cell-surface area, volume, and sphericity. The cell-surface area of $\mathrm{CD} 11 \mathrm{c}^{+} \mathrm{DCs}$ and $\mathrm{MHC}-\mathrm{II}^{+}$mature APCs significantly decreasing following inflammation (CD11c: $987.6 \pm$ $46.5 \mu \mathrm{m}^{2}$ with a median of 923.9 to $505.6 \pm 14.7 \mu \mathrm{m}^{2}$ and a median of $412.2 \mu \mathrm{m}^{2}, P<0.001$; MHC-II: $1518.6 \pm$ $75.3 \mu \mathrm{m}^{2}$ with a median of 1341.5 to $745.7 \pm 21.1 \mu \mathrm{m}^{2}$ and a median of $\left.616.0 \mu \mathrm{m}^{2}, P<0.001\right)$. Cell-surface volume also significantly decreased following inflammation (CD11c: $1458.9 \pm 84.5 \mu \mathrm{m}^{3}$ with a median of 1251.8 to $691.5 \pm$ $27.7 \mu \mathrm{m}^{3}$ and a median of $470.6 \mu \mathrm{m}^{3}, P<0.001$; MHC-II: $2835.6 \pm 143.0 \mu \mathrm{m}^{3}$ with a median of 2586.2 to $1348.5 \pm$ $51.8 \mu^{3}$ and a median of $\left.948.1 \mu \mathrm{m}^{3}, P<0.001\right)$. Furthermore, cell sphericity $3 \mathrm{D}$ analysis revealed a significant increase in sphericity during inflammation in both subpopulations (CD11c: $0.62 \pm 0.01$ with a median of 0.61 to $0.72 \pm 0.00$ and a median of $0.73, P<0.001$; MHC-II: $0.65 \pm 0.01$ with a median of 0.66 to $0.75 \pm 0.00$ and a median of 0.76, $P<0.001$; Supplemental Fig. S4F-H).

\section{Analysis of cell kinetics and motility parameters}

\section{Corneal intravital multiphoton microscopy during steady state}

We next sought to track and analyze CL kinetics in transgenic mice during steady state via IV-MPM. Variations in temperature have previously been shown to affect leukocyte function in other tissues (64-66). Likewise, when 
corneal temperature was not regulated, initial IV-MPM imaging revealed no cell movement in the corneas of MHC-II ${ }^{\text {eGFP }}$ mice (Supplemental Video 4). The maintenance of the correct physiologic surface temperature of $34^{\circ} \mathrm{C}$ throughout imaging proved paramount, enabling the capture of cell movement of CLs during steady state (Supplemental Video S5), akin to the constant sampling behavior of resident DCs (63), as previously shown in the epidermis (67). Local steady-state corneal $\mathrm{CD} 11 \mathrm{c}^{+}$and MHC-II ${ }^{+}$leukocytes exhibited no directionality and little to no displacement in both lateral $(x-y)$ and anteriorposterior $(z)$ axes during steady state (Fig. $3 A, B$ ). The analysis of videos where the corneal temperature falls outside of the physiologic temperature range $\left(33-35^{\circ} \mathrm{C}\right)$ revealed the importance of tight temperature regulation on CL sampling movements during steady state. Analysis of mean track velocity from CLs where the temperature of the cornea was not within the physiologic range revealed the inability to measure correctly cell motility (lack of centroid movement) and kinetics (track speed mean: $0.05 \pm 0.02$ vs. $1.64 \pm 0.07 \mu \mathrm{m} / \mathrm{min}, P<0.001$; and track displacement length: $8.67 \pm 0.47 v s .4 .20 \pm 0.33 \mu \mathrm{m} / \mathrm{min}$, not significant) in the steady-state cornea (Supplemental Fig. S5A). Quantification of cell motility during steady state revealed that although $\mathrm{CD} 11 \mathrm{c}^{+}$DCs exhibit increased track length compared with $\mathrm{MHC}-\mathrm{II}^{+}$APCs $\left(\mathrm{CD}_{11}{ }^{+}: 64.4 \pm 8.7 \mu \mathrm{m} ; \mathrm{MHC}^{-\mathrm{II}^{+}}: 28.1 \pm 2.8, P<0.001\right.$; Fig. $3 C$ ), both $C D 11 c^{+}$DCs and MHC-II ${ }^{+}$APCs show minimal displacement length $\left(\mathrm{CD} 11 \mathrm{c}^{+}: 4.64 \pm 0.56 \mu \mathrm{m} ; \mathrm{MHC}^{-\mathrm{II}^{+}}\right.$: $4.09 \pm 0.39, P=0.51$; Fig. $3 D$ ), exhibiting low $3 \mathrm{D}$ instantaneous velocity $\left(\mathrm{CD} 11 \mathrm{c}^{+}: 0.96 \pm 0.02 \mu \mathrm{m} / \mathrm{min}\right.$; MHC-II $: 0.99 \pm 0.02, P=0.26$; Fig. $3 E$ ) and a low mean

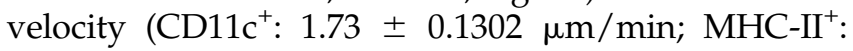

$1.62 \pm 0.08, P=0.53 ;$ Fig. $3 F)$. Taken together, our data demonstrate that CLs are sessile, exhibiting only sampling movement, in the steady-state cornea.

\section{Corneal intravital multiphoton microscopy during inflammation}

Directional migration, including recruitment and the trajectory within sites of injury, is fundamental to leukocyte function. Thus, we next sought to investigate kinetics of the specific leukocyte population $\left(\mathrm{CD} 11 \mathrm{c}^{+}\right.$and $\left.\mathrm{MHC}-\mathrm{II}^{+}\right)$ after inflammation. In CD11 ${ }^{\mathrm{eGFP}}$ and MHC-II ${ }^{\mathrm{eGFP}}$ mice, the range of motility captured includes large cells traveling slowly in one direction/plane across the anterior stroma (Fig. 4A, B, open arrows; and Supplemental Videos S6 and S7) to smaller cells with higher velocity, exhibiting a more random, less directional movement through the stroma (Fig. 4, white arrowheads), and less motile cells that mostly exhibit sampling of the microenvironment (Fig. 4A, C, dashed arrow). The analysis of videos, where the corneal temperature falls outside of the physiologic temperature range $\left(33-35^{\circ} \mathrm{C}\right)$, further revealed the importance of tight temperature regulation on CL kinetics during keratitis, with evident differences in track speed mean $(1.06 \pm 0.04$ vs. $2.79 \pm 0.06 \mu \mathrm{m} / \mathrm{min}, P<0.001)$ and displacement length $(5.69 \pm 0.40$ vs. $10.96 \pm 0.47 \mu \mathrm{m} / \mathrm{min}, P<0.01)$ compared with the tightly regulated data (Supplemental Fig. S5B). The increase in tactile cell movement of migratory CD11 ${ }^{+}$DCs (Fig. $4 A$ and Supplemental Video S6) and MHC-II ${ }^{+}$APCs (Fig. 4B and Supplemental Video S7) was noted in both lateral $(x-y)$, as well as anterior-posterior ( $z$; Supplemental Video S8) planes within the corneal
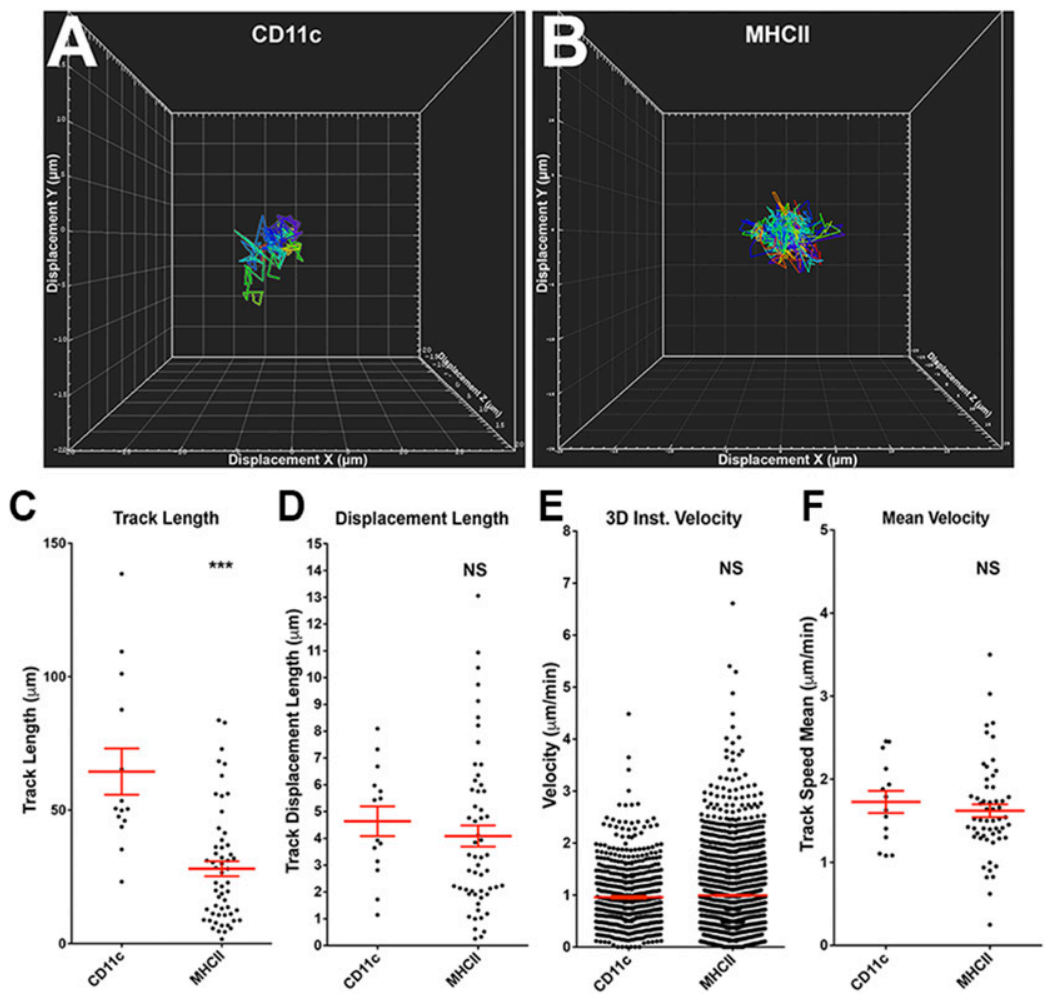

Figure 3. Analysis of steady-state cell kinetics and motility parameters. $A, B)$ Displacement tracks of steady-state corneal $(A) \mathrm{CD}_{11 \mathrm{c}^{+}}$and $(B)$ $\mathrm{MHC}^{-\mathrm{II}^{+}}$leukocytes reveal minimal directionality under steady state. $C-F)$ Track length $(C)$; displacement length $(D)$; instantaneous velocity $(E)$; and mean velocity $(F)$ results of CD11c- and MHC-II-positive cell tracks are presented as means \pm SEM, Student's $t$ test. $* * * P<0.01$. 

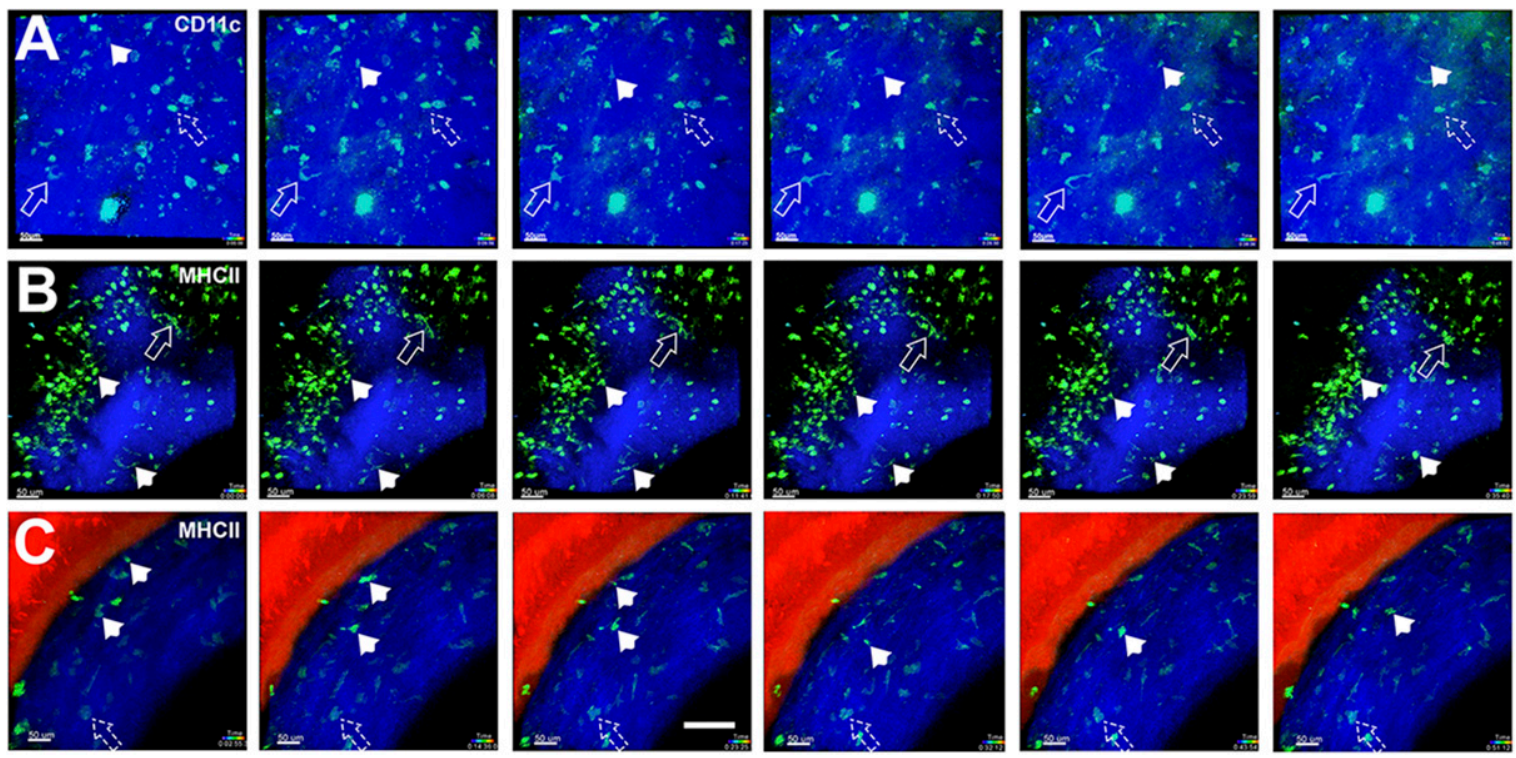

Figure 4. En face $(A, B)$ and transverse $(C)$ time-course images from CD11c and MHC-II transgenic cornea postcautery burn reveal varying degrees of kinetics among CLs. Cell motility ranged from largely static cells displaying sampling behavior: morphologic change with no movement [dashed arrows $(A, C)$ ]; large, slow cells [open arrows $(A, B)$ ]; to small, fast cells [white arrowheads throughout total image time [49 $\mathrm{min}(A), 36 \mathrm{~min}(B)$, and $51 \mathrm{~min}(C)$ ]. Original scale bars, $50 \mu \mathrm{m}$, time-stamp on bottom-right of each image.

stroma. As such movement would be best highlighted in a cross-sectional view, we captured xyzt stacks of a transverse section of the cornea. This highlighted that the majority of $\mathrm{GFP}^{+}$cells appearing to be either static or having little movement when observed en face (Fig. 4A, $B$ ) may indeed be actively migrating in the anterior-posterior axis through the cornea in oblique cross-sectional views (Fig. 4C and Supplemental Videos S6-8). Interestingly, analysis of epithelial ${\mathrm{MHC}-\mathrm{II}^{+}}$transgenic corneas revealed APC kinetics to differ from APCs distributed in the corneal stroma, where cells crawl at a slow pace, extending and retracting processes along their path in the epithelium (Supplemental Video S9). Analysis of inflamed corneas in $\mathrm{CX}_{3} \mathrm{CR} 1^{\mathrm{GFP} / \mathrm{GFP}}$ mice demonstrated minimal lateral and anterior-posterior cell displacement (Supplemental Video S10) following inflammation.

A significant difference in cell directionality and displacement was noted in corneas of CD11 $c^{\text {eYFP }}$ and MHC-II ${ }^{\text {eGFP }}$ transgenic mice following acute inflammation (Fig. $5 A, B$ ). The average track length of $C D 11 c^{+}$DCs was $60.5 \pm 3.1 \mu \mathrm{m}$ (median: $49.7 \mu \mathrm{m}$; not significant when compared with steady state); whereas, MHC- $-\mathrm{II}^{+}$track length mean was greater at $74.3 \pm 2.0 \mu \mathrm{m}$ (median: $72.9 \mu \mathrm{m}$; $P<0.001$ compared with steady state; Fig. 5C). Interestingly, total displacement length showed CD11 $\mathrm{c}^{+} \mathrm{DCs}$ had greater displacement $(16.6 \pm 1.4 \mu \mathrm{m}$, a median of $9.9 \mu \mathrm{m})$ compared with MHC-II ${ }^{+}$leukocytes $(9.0 \pm 0.4 \mu \mathrm{m}$, median of $6.5 \mu \mathrm{m}, P<0.001$ ) in inflamed corneas, as well as compared with their respective steady-state values. This variation between CD11c and MHC-II track length following inflammation was also significant $(P<0.01$; Fig. $5 D$ ). Analysis of cellular velocity revealed significant differences in instantaneous velocity for $\mathrm{CD}_{11 c^{+}}(1.46 \pm$ $0.02 \mu \mathrm{m} / \mathrm{min}$, median: $0.94 \mu \mathrm{m} / \mathrm{min}$ ) and MHC-II ${ }^{+}$cells (1.76 $\pm 0.01 \mu \mathrm{m} / \mathrm{min}$, median: $1.34 \mu \mathrm{m} / \mathrm{min})$ between groups and when compared with steady state $(P<0.001$; Fig. 5E). Alterations in mean velocity are similarly increased following acute inflammation in $\mathrm{CD}_{11} \mathrm{c}^{+}(1.91 \pm$ $0.07 \mu \mathrm{m} / \mathrm{min}$, median: $1.62 \mu \mathrm{m} / \mathrm{min}$ ) and $\mathrm{MHC}-\mathrm{II}^{+}$ leukocytes $(2.97 \pm 0.07 \mu \mathrm{m} / \mathrm{min}$, median: $2.72 \mu \mathrm{m} / \mathrm{min})$. Furthermore, MHC- $\mathrm{II}^{+}$cell velocity correlated with displacement $(r=0.2758, P<0.001)$ and track length $(r=$ $0.3307, P<0.001)$. Mean velocity of CD11c ${ }^{+}$leukocytes did not reach significance when compared with steady state $(1.64 \pm 0.07 \mu \mathrm{m} / \mathrm{min}$, median: $1.53 \mu \mathrm{m} / \mathrm{min}$; Fig. $5 F)$.

Analysis of active, migratory leukocytes revealed a statistically significant difference in the meandering index between $\mathrm{CD} 11 \mathrm{c}^{+}(0.35 \pm 0.02$, median: 0.31$)$ and $\mathrm{MHC}-\mathrm{II}^{+}$ cells $(0.23 \pm 0.01$, median: $0.17 ; P<0.001)$ following acute thermal injury (Fig. 5G). Taken together, our results also highlight that whereas MHC-II ${ }^{+}$leukocytes have a greater track length and mean velocity, $\mathrm{CD} 11 \mathrm{c}^{+} \mathrm{APC}$ are more greatly affected in terms of displacement and directionality following corneal inflammation.

\section{DISCUSSION}

Herein, we detail the necessary conditions and methodology required for repetitive intravital immunoimaging of the cornea and present detailed analyses of cellular leukocyte kinetics during both steady state and inflammation. Furthermore, we show detailed 3D alterations of CLs, including cell volume, surface area, and sphericity during steady state and inflammation.

Despite the increased spatial and temporal resolution afforded by IV-MPM and the plethora of the transgenic lines expressing endogenous fluorescence under promoters for various leukocyte types, the study of singlecell dynamics of leukocytes within an intact corneal 


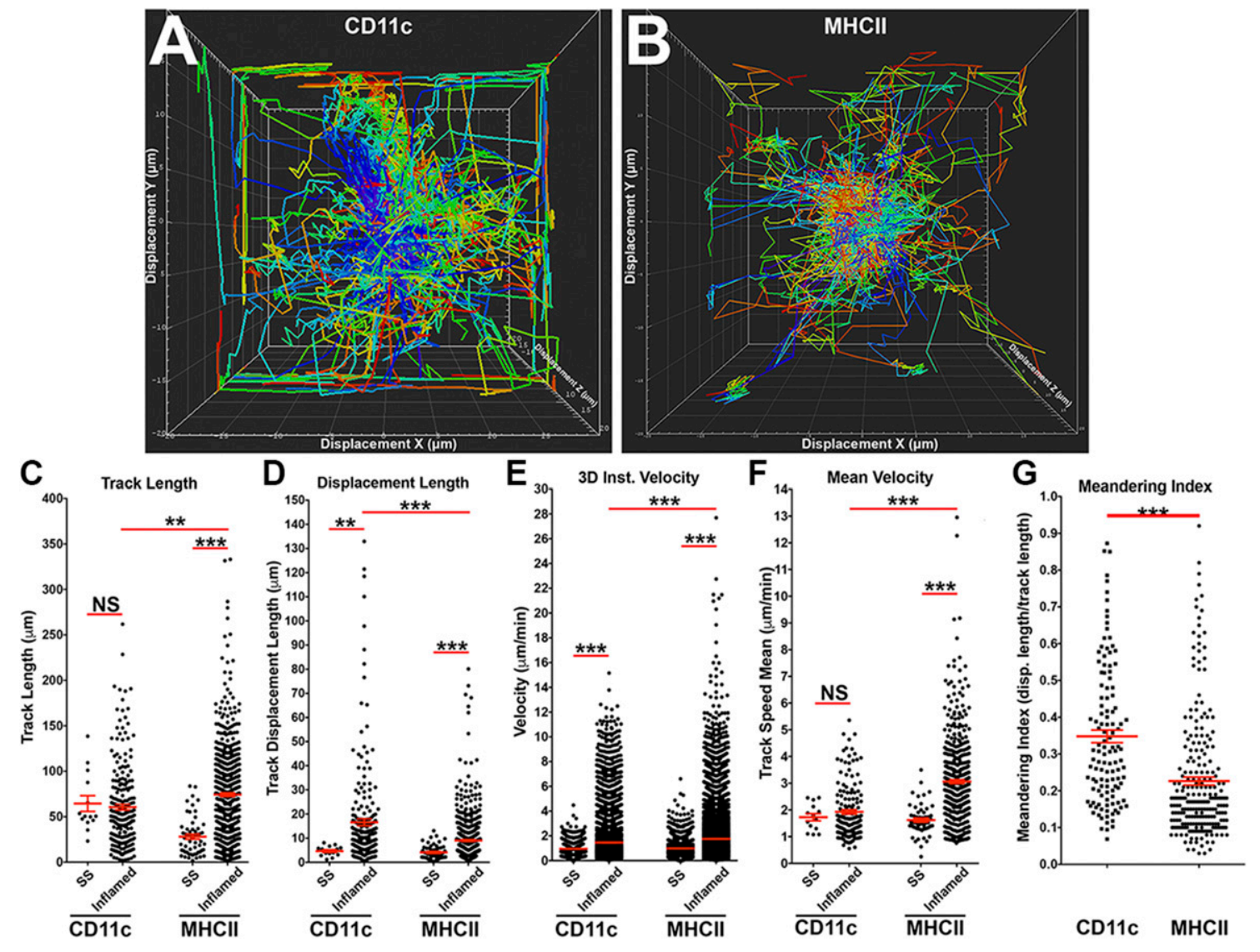

Figure 5. Analysis of cell kinetics and motility parameters following acute inflammation. $A, B)$ Displacement tracks of CD11c ${ }^{+}(A)$ and MHC-II ${ }^{+}(B)$ CLs reveal multidirectional movement following thermal cautery burn. $\left.C-G\right)$ Track length $(C)$, displacement length $(D)$, instantaneous velocity $(E)$, mean velocity $(F)$, and meandering index $(G)$ of CLs; means \pm SEM, 1 -way ANOVA. $* * P<$ $0.01, * * * P<0.001$.

microenvironment has remained elusive. An open eye, necessary for imaging purposes, decreases its temperature, leading to alterations in the kinetics of leukocytes therein. Therefore, the specific regulation of the eye temperature requires separate maintenance from body temperature for correct analysis of CLs kinetics during steady state and keratitis. Our model uses a stereotactic stage and a sealed chamber around the eye, preventing dehydration of the eye and thermal laser burns during this long-term imaging procedure, to regulate corneal temperature while compensating for blinking, major drift, nystagmus, and ocular pulsations.

The current literature using IV-MPM to investigate the cornea and limbus includes use of vital dyes (68), injection of antibodies (54), or second harmonic generation to assess keratocytes and the corneal proper ex vivo (49). The setup of Steven et al. (54), investigating leukocyte transmigration into lymphatic vessels in the peripheral cornea and limbus, was not temperature controlled, which as we demonstrate, is necessary to visualize central CL kinetics in a noninvasive manner, and furthermore, did not use transgenic mice. More recently, 2 studies have used MPM to investigate endogenously, fluorescently labeled neutrophil kinetics on the ocular surface of mice $(69,70)$. Whereas the setup used by Ueta et al. (69) for analyzing the cornea likely maintains the correct ocular surface temperature required for analysis of CLs, it is highly invasive, as the entire eye is dislocated to immobilize the cornea and compensate/ correct for the various image stability issues (e.g., drift and ocular pulsations) and positions the mouse on its back for the entire length of imaging inside a dark, $37^{\circ} \mathrm{C}$ box. Furthermore, the nature of vessels and corneal nerves in this preparation is unknown. Other attempts of in vivo imaging of CLs include a report by Lee et al. (71), who used epifluorescent intravital microscopy to show increased cell infiltration after inflammation but not cell motility as a result of lack of temperature control, whereas another report using intravital imaging of bone marrow chimeric mice similarly described an influx of $\mathrm{eGFP}^{+}$leukocytes into the murine cornea following induction of LPSinduced keratitis by confocal microscopy (72). In light of the need for a stable, feasible, and reproducible corneal IV-MPM technique to investigate migratory leukocyte kinetics in a physiologic corneal microenvironment, the present study provides the necessary conditions required for long-term, minimally invasive IV-MPM imaging.

IV-MPM analysis of transgenic animals allowed us to investigate CLs in their natural state and following inflammation. Previous ex vivo whole-mount corneal-staining analyses of CLs revealed that DCs and macrophages are distributed throughout the steady-state cornea $(19,22)$. Our results, both ex vivo and in vivo, are in line with these reports. We found both dendritiform-when localized mostly within the epithelium and anterior stroma-and low 
sphericity amoeboid-spread out and flattened-when localized within the densely packed stromal matrix (73) CD11 $\mathrm{c}^{+}$DCs and MHC-II ${ }^{+}$APCs throughout the imaged cornea. Furthermore, morphologic analyses highlight differences between $\mathrm{CD} 11 \mathrm{c}^{+}$and $\mathrm{MHC}-\mathrm{II}^{+} \mathrm{CL}$ in steady state. As 2D morphologic analysis is inherently dependent on placement of measurement points, which in the case of DCs, will include the long processes, it is not a clear and standardized method indicative of true cell morphology. Accordingly, 3D morphologic analysis, including cell volume and sphericity, reveals differences among steady-state CL populations, otherwise not seen with 2D analysis, under steady-state conditions. Furthermore, analysis of leukocyte populations expressing endogenous fluorescence in vivo, naturally allows for better analysis of leukocyte morphologic alterations that result from activation following inflammation with a more uniform signal compared with postfixed and stained corneal flat mounts.

Acute inflammation significantly alters CL size and morphology. Our analyses of cellular morphologic parameters reveal a significant decrease in both area and volume of $\mathrm{CD}_{11 \mathrm{c}^{+}}$and $\mathrm{MHC}-\mathrm{II}^{+}$leukocytes. Following inflammation, we note that CLs develop a spherical phenotype. This is in line with the amoeboid shapes that migratory leukocytes appropriate during chemotaxis through an extracellular space matrix, described to be via formation of actin-rich protrusions and a leading edge $(63,74)$. Interestingly, we found the greatest morphologic change among CLs following inflammation to be in $\mathrm{CD} 11 \mathrm{c}^{+}$leukocytes compared with steady state. Whereas $\mathrm{CX}_{3} \mathrm{CR} 1^{+}$leukocyte size, surface area, and volume parameters were altered compared with steady state, more time following inflammation is likely required to observe alterations in cell sphericity across these cells.

Resident populations of DCs within the skin and gut epithelium have been shown to be sessile $(55,75)$, whereas dermal DCs actively crawl through the interstitial space with a mean velocity of $3.7 \pm 0.3 \mu \mathrm{m} / \mathrm{min}$ (76). We show that CLs are sessile during steady-state conditions, exhibiting no displacement and directionality. The lack of migratory movement during steady state may be, in part, a result of active mechanisms of corneal immune privilege, the densely packed collagenous structure of the cornea, resulting in limited extracellular space to allow migration and absence of chemotactic cytokines. In concordance, studies have highlighted that chemokines in the cornea are altered following local injury, herpes simplex virus 1 infection, and transplantation $(77,78)$.

Analysis of CD11c ${ }^{\mathrm{eYFP}}$ and MHC-II ${ }^{\mathrm{eGFP}}$ CL kinetics revealed a heterogeneous array of cells exhibiting various degrees of motility, directionality, velocity, displacement length, and meandering index. $\mathrm{MHC}-\mathrm{II}^{+}$leukocytes were more motile, exhibited greater velocity, but had a lower displacement compared with $\mathrm{CD}_{11 c^{+}}$leukocytes, which exhibited less motility, a greater range in displacement, but a lower velocity. Further investigations into possible kinetic differences between macrophage and DC populations within the cornea are required to determine the kinetics of each subpopulation. Our results highlight CL populations to possess differing meandering indices but also reveal subpopulations of cells expressing varying degrees of directionality. Low meandering index values $(<0.4)$ and lack of directionality observed in all CL populations after thermal injury may be a result of the nature of the injury itself. Induction of 5 light burns to the cornea likely results in multiple sources of chemokine and cytokine release and in turn, the multidirectional chemotactic migration seen in our results. Another likely confounding factor in the change in cell motility is the loss of corneal nerve fibers in these locations, with close proximity between CLs and corneal nerves having been reported in the steady-state cornea $(27,79)$. Other inflammatory states, such as single epithelial injury or suture placement, resulting in a single source of chemokine release, will likely show directional chemotactic migration. Leukocyte subpopulations within the $\mathrm{CD} 11 \mathrm{c}^{+} \mathrm{DCs}$ (mature vs. immature) and MHC- $\mathrm{II}^{+}$mature APCs (macrophages vs. other APCs) may explain the heterogeneous distribution of our data. Circulating or local immature APCs that infiltrate the damaged areas of the cornea may have increased directionality and a high meandering index, as opposed to already activated mature APCs. The current method of CL investigation is unable to discern steady-state CLs from infiltrating myeloid-derived cells.

The current consensus on leukocyte populations distributed throughout the cornea includes the following: epithelial and stromal conventional $\mathrm{CD} 45^{+} \mathrm{CD} 11 \mathrm{c}^{+} \mathrm{DCs}$, $\mathrm{CD} 11 \mathrm{~b}^{+} \mathrm{F} 4 / 80^{+}$stromal macrophages, and $\mathrm{B} 22 \mathrm{O}^{+} \mathrm{CD} 11 \mathrm{c}^{\text {lo }}$ putative stromal pDCs during steady state, with inflammation resulting in influx of circulating leukocytes (neutrophils, DCs, and macrophages), whereas CLs undergo maturation and increase MHC-II, CD80, and CD86 expression. We refer to CD11 $\mathrm{c}^{+}$leukocytes as DCs and MHC-II ${ }^{+}$leukocytes as mature APCs throughout the manuscript. Whereas our flow analyses of $\mathrm{CD} 11 \mathrm{c}^{+}$leukocytes phenotypically align these cells with DCs based on cell-surface markers, the shared myeloid precursor origin of DCs and macrophages (80), in addition to phenotypical changes that leukocytes undergo during inflammation, highlight the necessity for functional testing and/or cellular origin analysis for categorical classification of $\mathrm{CD} 11 \mathrm{c}^{+}$ and MHC-II ${ }^{+}$CLs investigated in our study (81).

The differences noted between $\mathrm{CX}_{3} \mathrm{CR} 1^{+}$leukocytes and other corneal APCs may be, in part, a result of their altered function in the homozygous transgenic mouse model. $\mathrm{CX}_{3} \mathrm{CR} 1$ homozygous mice are $\mathrm{CX}_{3} \mathrm{CR} 1$ deficient with both alleles of the $\mathrm{CX}_{3} \mathrm{CR} 1$ gene replaced by the eGFP reporter gene, whereas $\mathrm{CX}_{3} \mathrm{CR} 1^{\mathrm{GFP} /+}$ animals retain a functional allele (58). The loss of a single allele is sufficient to alter cell leukocyte activity in injury / disease states (82). Furthermore, fractalkine signaling plays important roles in leukocyte distribution (23) and signal transmission between immune cell and nerves within the cornea (27). The minimal lateral and anterior-posterior cell displacement noted herein may, therefore, be a result of the deficiency of $\mathrm{CX}_{3} \mathrm{CR} 1$.

DC motility has previously been investigated with IV-MPM in the murine lung, with a recent report finding that DC velocity increased from $0.6 \mu \mathrm{m} / \mathrm{min}$ in steady state to $\sim 2 \mu \mathrm{m} / \mathrm{min}$ in living-tissue vibratome slices of airway postadenovirus IL-1 $\beta$-induced inflammation (83). A report investigating ear-skin APC surveillance further 
revealed that the mean velocity of dermal DCs decreases from a resting state of $\sim 3.4$ to $2 \mu \mathrm{m} / \mathrm{min}$ following systemic LPS challenge (76). DCs in the pancreas are predominantly slow moving, with a mean velocity $\sim 3 \mu \mathrm{m} / \mathrm{min}$ (84). Our data align with these reports with CLs while sessile under steady-state conditions, increasing their velocity and displacement following acute thermal injury. DC velocity in T cell areas of the popliteal lymph nodes has been reported to be $6.6 \mu \mathrm{m} / \mathrm{min}$ (43), in line with reports from explanted lymph nodes $(5.9 \pm 1.0 \mu \mathrm{m} / \mathrm{min})$ (85), whereas DC crawling speeds within the inguinal lymph nodes vary from a sessile state within the T-zone to a $2-4 \mu \mathrm{m} / \mathrm{min}$ crawl within the perifollicular and B-zone location (55). Finally, analysis of human DC motility in the lung-tissue models revealed greater DC displacement in combination with increased cell velocity mean in response to LPS, Pam3CSK4, and CCL2 (86). The differences in DC velocities in response to inflammation are likely indicative of the differing biology, localization, phenotype, and possibly, function of DCs within these different tissues.

An overactive response to chronic inflammation within the eye can be detrimental to vision. The methodology described herein allows for the investigation of kinetics and in turn, functional changes of APC populations in the cornea, including local cell-cell interactions in various states of inflammation and tissue damage, such as in infectious keratitis after corneal transplantation, or in dryeye disease. The investigation of such alterations of corneal immunology may aid in elucidating underlying regulatory mechanisms behind corneal immune privilege. It will also allow the investigation of potential, new antiinflammatory factors toward ameliorating detrimental pathophysiological conditions affecting the cornea during diseased states.

\section{ACKNOWLEDGMENTS}

Financial support was provided by U.S. National Institutes of Health, National Eye Institute Grants R01-EY022695, K08EY020575, and K12-EY016335 (to P.H.); Research to Prevent Blindness Career Development Award (to P.H.); and Fight for Sight Grant-in-Aid (to P.H.). The authors are grateful to Dr. Ulrich H. von Andrian (Harvard Medical School) for his critical consultations and suggestions in experimental design, and to the Harvard Medical School Center for Immune Imaging. The authors declare no conflicts of interest.

\section{AUTHOR CONTRIBUTIONS}

Y. Seyed-Razavi and P. Hamrah designed the research and analyzed the data; Y. Seyed-Razavi, D. Mantopoulos, L. Zheng, S. Massberg, D. L. Harris, and P. Hamrah performed the research; M. J. Lopez and V. G. Sendra contributed new analytic tools; and Y. Seyed-Razavi, M. J. Lopez, D. L. Harris, and P. Hamrah wrote the manuscript.

\section{REFERENCES}

1. Streilein, J. W. (2003) New thoughts on the immunology of corneal transplantation. Eye (Lond.) 17, 943-948
2. Streilein, J. W. (1999) Regional immunity and ocular immune privilege. Chem. Immunol. 73, 11-38

3. Niederkorn, J. Y. (2003) The immune privilege of corneal grafts. J. Leukoc. Biol. 74, 167-171

4. Streilein, J. W., Ohta, K., Mo, J. S., and Taylor, A. W. (2002) Ocular immune privilege and the impact of intraocular inflammation. DNA Cell Biol. 21, 453-459

5. Streilein, J. W. (2003) Ocular immune privilege: therapeutic opportunities from an experiment of nature. Nat. Rev. Immunol. 3, 879-889

6. Ambati, B. K., Nozaki, M., Singh, N., Takeda, A., Jani, P. D., Suthar, T., Albuquerque, R. J., Richter, E., Sakurai, E., Newcomb, M. T., Kleinman, M. E., Caldwell, R. B., Lin, Q., Ogura, Y., Orecchia, A., Samuelson, D. A., Agnew, D. W., St Leger, J., Green, W. R., Mahasreshti, P. J., Curiel, D. T., Kwan, D., Marsh, H., Ikeda, S., Leiper, L. J., Collinson, J. M., Bogdanovich, S., Khurana, T. S., Shibuya, M., Baldwin, M. E., Ferrara, N., Gerber, H. P., De Falco, S., Witta, J., Baffi, J. Z., Raisler, B. J., and Ambati, J. (2006) Corneal avascularity is due to soluble VEGF receptor-1. Nature 443, 993-997

7. Medawar, P. B. (1961) Immunological tolerance. Nature 189, 14-17

8. Streilein, J. W. (2003) Ocular immune privilege: the eye takes a dim but practical view of immunity and inflammation. J. Leukoc. Biol. 74, 179-185

9. Forrester, J. V., and Xu, H. (2012) Good news-bad news: the yin and yang of immune privilege in the eye. Front. Immunol. 3, 338

10. Pearlman, E., Sun, Y., Roy, S., Karmakar, M., Hise, A. G., Szczotka-Flynn, L., Ghannoum, M., Chinnery, H. R., McMenamin, P. G., and Rietsch, A. (2013) Host defense at the ocular surface. Int. Rev. Immunol. 32, 4-18

11. Liu, Y., Hamrah, P., Zhang, Q., Taylor, A. W., and Dana, M. R. (2002) Draining lymph nodes of corneal transplant hosts exhibit evidence for donor major histocompatibility complex (MHC) class II-positive dendritic cells derived from MHC class II-negative grafts. J. Exp. Med. 195, 259-268

12. Hamrah, P., Zhang, Q., Liu, Y., and Dana, M. R. (2002) Novel characterization of MHC class II-negative population of resident corneal Langerhans cell-type dendritic cells. Invest. Ophthalmol. Vis. Sci. 43, 639-646

13. Benhar, I., London, A., and Schwartz, M. (2012) The privileged immunity of immune privileged organs: the case of the eye. Front. Immunol. 3, 296

14. Hamrah, P., and Dana, R. (2010) Antigen-presenting cells in the eye and ocular surface A2 - dartt, darlene A. In Encyclopedia of the Eye, pp. 120-127, Academic Press, Oxford, United Kingdom

15. Forrester, J. V., Xu, H., Kuffová, L., Dick, A. D., and McMenamin, P. G. (2010) Dendritic cell physiology and function in the eye. Immunol. Rev. 234, 282-304

16. Knickelbein, J. E., Buela, K. A., and Hendricks, R. L. (2014) Antigenpresenting cells are stratified within normal human corneas and are rapidly mobilized during ex vivo viral infection. Invest. Ophthalmol. Vis. Sci. 55, 1118-1123

17. Knickelbein, J. E., Watkins, S. C., McMenamin, P. G., and Hendricks, R. L. (2009) Stratification of antigen-presenting cells within the normal cornea. Ophthalmol. Eye Dis. 1, 45-54

18. Hamrah, P., and Dana, M. R. (2007) Corneal antigen-presenting cells. Chem. Immunol. Allergy 92, 58-70

19. Hamrah, P., Liu, Y., Zhang, Q., and Dana, M. R. (2003) The corneal stroma is endowed with a significant number of resident dendritic cells. Invest. Ophthalmol. Vis. Sci. 44, 581-589

20. Hamrah, P., Liu, Y., Zhang, Q., and Dana, M. R. (2003) Alterations in corneal stromal dendritic cell phenotype and distribution in inflammation. Arch. Ophthalmol. 121, 1132-1140

21. Nakamura, T., Ishikawa, F., Sonoda, K. H., Hisatomi, T., Qiao, H., Yamada, J., Fukata, M., Ishibashi, T., Harada, M., and Kinoshita, S. (2005) Characterization and distribution of bone marrow-derived cells in mouse cornea. Invest. Ophthalmol. Vis. Sci. 46, 497-503

22. Brissette-Storkus, C. S., Reynolds, S. M., Lepisto, A. J., and Hendricks, R. L. (2002) Identification of a novel macrophage population in the normal mouse corneal stroma. Invest. Ophthalmol. Vis. Sci. 43, 2264-2271

23. Chinnery, H. R., Ruitenberg, M. J., Plant, G. W., Pearlman, E., Jung, S., and McMenamin, P. G. (2007) The chemokine receptor CX3CR1 mediates homing of MHC class II-positive cells to the normal mouse corneal epithelium. Invest. Ophthalmol. Vis. Sci. 48, 1568-1574

24. Yamagami, S., Ebihara, N., Usui, T., Yokoo, S., and Amano, S. (2006) Bone marrow-derived cells in normal human corneal stroma. Arch. Ophthalmol. 124, 62-69 
25. Yamagami, S., Usui, T., Amano, S., and Ebihara, N. (2005) Bone marrow-derived cells in mouse and human cornea. Comea 24(Suppl 8), S71-S74

26. Yamagami, S., Yokoo, S., Usui, T., Yamagami, H., Amano, S., and Ebihara, N. (2005) Distinct populations of dendritic cells in the normal human donor corneal epithelium. Invest. Ophthalmol. Vis. Sci. 46, 4489-4494

27. Seyed-Razavi, Y., Chinnery, H. R., and McMenamin, P. G. (2014) A novel association between resident tissue macrophages and nerves in the peripheral stroma of the murine cornea. Invest. Ophthalmol. Vis. Sci. 55, 1313-1320

28. Hattori, T., Chauhan, S. K., Lee, H., Ueno, H., Dana, R., Kaplan, D. H., and Saban, D. R. (2011) Characterization of Langerin-expressing dendritic cell subsets in the normal cornea. Invest. Ophthalmol. Vis. Sci. 52, 4598-4604

29. Sosnová, M., Bradl, M., and Forrester, J. V. (2005) CD34+ corneal stromal cells are bone marrow-derived and express hemopoietic stem cell markers. Stem Cells 23, 507-515

30. Cahalan, M. D., Parker, I., Wei, S. H., and Miller, M. J. (2002) Twophoton tissue imaging: seeing the immune system in a fresh light. Nat. Rev. Immunol. 2, 872-880

31. Von Andrian, U. H., and Mempel, T. R. (2003) Homing and cellular traffic in lymph nodes. Nat. Rev. Immunol. 3, 867-878

32. Mempel, T. R., Scimone, M. L., Mora, J. R., and von Andrian, U. H. (2004) In vivo imaging of leukocyte trafficking in blood vessels and tissues. Curr. Opin. Immunol. 16, 406-417

33. Bueno, J. M., Gualda, E. J., Giakoumaki, A., Pérez-Merino, P., Marcos, S., and Artal, P. (2011) Multiphoton microscopy of ex vivo corneas after collagen cross-linking. Invest. Ophthalmol. Vis. Sci. 52, 5325-5331

34. Park, C. Y., Lee, J. K., and Chuck, R. S. (2015) Second harmonic generation imaging analysis of collagen arrangement in human cornea. Invest. Ophthalmol. Vis. Sci. 56, 5622-5629

35. Benninger, R. K., and Piston, D. W. (2013) Two-photon excitation microscopy for the study of living cells and tissues. Curr. Protoc. Cell Biol. Chapter 4, Unit 4.11.1-Unit 4.11.24

36. Piston, D. W. (1999) Imaging living cells and tissues by two-photon excitation microscopy. Trends Cell Biol. 9, 66-69

37. Denk, W., Strickler, J. H., and Webb, W. W. (1990) Two-photon laser scanning fluorescence microscopy. Science 248, 73-76

38. Zoumi, A., Yeh, A., and Tromberg, B. J. (2002) Imaging cells and extracellular matrix in vivo by using second-harmonic generation and two-photon excited fluorescence. Proc. Natl. Acad. Sci. USA 99, 11014-11019

39. Teng, S. W., Tan, H. Y., Peng, J. L., Lin, H. H., Kim, K. H., Lo, W., Sun, Y., Lin, W. C., Lin, S. J., Jee, S. H., So, P. T., and Dong, C. Y. (2006) Multiphoton autofluorescence and second-harmonic generation imaging of the ex vivo porcine eye. Invest. Ophthalmol. Vis. Sci. 47, 1216-1224

40. Mantopoulos, D., Cruzat, A., and Hamrah, P. (2010) In vivo imaging of corneal inflammation: new tools for clinical practice and research. Semin. Ophthalmol. 25, 178-185

41. Morishige, N., Wahlert, A. J., Kenney, M. C., Brown, D. J., Kawamoto, K., Chikama, T., Nishida, T., and Jester, J. V. (2007) Second-harmonic imaging microscopy of normal human and keratoconus cornea. Invest. Ophthalmol. Vis. Sci. 48, 1087-1094

42. Miller, M. J., Wei, S. H., Cahalan, M. D., and Parker, I. (2003) Autonomous T cell trafficking examined in vivo with intravital twophoton microscopy. Proc. Natl. Acad. Sci. USA 100, 2604-2609

43. Mempel, T. R., Henrickson, S. E., and Von Andrian, U. H. (2004) T-Cell priming by dendritic cells in lymph nodes occurs in three distinct phases. Nature 427, 154-159

44. Roediger, B., Ng, L. G., Smith, A. L., Fazekas de St Groth, B., and Weninger, W. (2008) Visualizing dendritic cell migration within the skin. Histochem. Cell Biol. 130, 1131-1146

45. Cho, K. W., Morris, D. L., DelProposto, J. L., Geletka, L., Zamarron, B., Martinez-Santibanez, G., Meyer, K. A., Singer, K., O’Rourke, R. W., and Lumeng, C. N. (2014) An MHC II-dependent activation loop between adipose tissue macrophages and CD4+ T cells controls obesity-induced inflammation. Cell Reports 9, 605-617

46. Turcotte, R., Alt, C., Mortensen, L. J., and Lin, C. P. (2014) Characterization of multiphoton microscopy in the bone marrow following intravital laser osteotomy. Biomed. Opt. Express 5, 3578-3588

47. Kolesnikov, M., Farache, J., and Shakhar, G. (2015) Intravital two-photon imaging of the gastrointestinal tract. J. Immunol. Methods 421, 73-80

48. Mori, A., Oguchi, Y., Okusawa, Y., Ono, M., Fujishima, H., and Tsubota, K. (1997) Use of high-speed, high-resolution thermography to evaluate the tear film layer. Am. J. Ophthalmol. 124, 729-735
49. Lo, W., Teng, S. W., Tan, H. Y., Kim, K. H., Chen, H. C., Lee, H. S., Chen, Y. F., So, P. T., and Dong, C. Y. (2006) Intact corneal stroma visualization of GFP mouse revealed by multiphoton imaging. Microsc. Res. Tech. 69, 973-975

50. Lyubovitsky, J. G., Spencer, J. A., Krasieva, T. B., Andersen, B., and Tromberg, B. J. (2006) Imaging corneal pathology in a transgenic mouse model using nonlinear microscopy. J. Biomed. Opt. 11, 014013

51. Han, M., Zickler, L., Giese, G., Walter, M., Loesel, F. H., and Bille, J. F. (2004) Second-harmonic imaging of cornea after intrastromal femtosecond laser ablation. J. Biomed. Opt. 9, 760-766

52. Tan, H. Y., Sun, Y., Lo, W., Lin, S. J., Hsiao, C. H., Chen, Y. F., Huang, S. C., Lin, W. C., Jee, S. H., Yu, H. S., and Dong, C. Y. (2006) Multiphoton fluorescence and second harmonic generation imaging of the structural alterations in keratoconus ex vivo. Invest. Ophthalmol. Vis. Sci. 47, 5251-5259

53. Ward, B. R., Jester, J. V., Nishibu, A., Vishwanath, M., Shalhevet, D., Kumamoto, T., Petroll, W. M., Cavanagh, H. D., and Takashima, A. (2007) Local thermal injury elicits immediate dynamic behavioural responses by corneal Langerhans cells. Immunology 120, 556-572

54. Steven, P., Bock, F., Hüttmann, G., and Cursiefen, C. (2011) Intravital two-photon microscopy of immune cell dynamics in corneal lymphatic vessels. PLoS One 6, e26253

55. Lindquist, R. L., Shakhar, G., Dudziak, D., Wardemann, H., Eisenreich, T., Dustin, M. L., and Nussenzweig, M. C. (2004) Visualizing dendritic cell networks in vivo. Nat. Immunol. 5, 1243-1250

56. Jung, S., Unutmaz, D., Wong, P., Sano, G., De los Santos, K., Sparwasser, T., Wu, S., Vuthoori, S., Ko, K., Zavala, F., Pamer, E. G., Littman, D. R., and Lang, R. A. (2002) In vivo depletion of CD11c+ dendritic cells abrogates priming of CD8+ T cells by exogenous cellassociated antigens. Immunity 17, 211-220

57. Boes, M., Cerny, J., Massol, R., Op den Brouw, M., Kirchhausen, T., Chen, J., and Ploegh, H. L. (2002) T-cell engagement of dendritic cells rapidly rearranges MHC class II transport. Nature 418, 983-988

58. Jung, S., Aliberti, J., Graemmel, P., Sunshine, M. J., Kreutzberg, G. W., Sher, A., and Littman, D. R. (2000) Analysis of fractalkine receptor CX (3) CR1 function by targeted deletion and green fluorescent protein reporter gene insertion. Mol. Cell. Biol. 20, 4106-4114

59. Efron, N., Young, G., and Brennan, N. A. (1989) Ocular surface temperature. Curr. Eye Res. 8, 901-906

60. Acosta, M. C., Belmonte, C., and Gallar, J. (2001) Sensory experiences in humans and single-unit activity in cats evoked by polymodal stimulation of the cornea. J. Physiol. 534, 511-525

61. Sharaf, R., Mempel, T. R., and Murooka, T. T. (2016) Visualizing the behavior of HIV-infected T cells in vivo using multiphoton intravital microscopy. Methods Mol. Biol. 1354, 189-201

62. Sumen, C., Mempel, T. R., Mazo, I. B., and von Andrian, U. H. (2004) Intravital microscopy: visualizing immunity in context. Immunity 21, 315-329

63. Lämmermann, T., and Germain, R. N. (2014) The multiple faces of leukocyte interstitial migration. Semin. Immunopathol. 36, 227-251

64. Hammarfjord, O., and Wallin, R. P. (2010) Dendritic cell function at low physiological temperature. J. Leukoc. Biol. 88, 747-756

65. Zgair, A. K. (2012) The effect of high temperature on the kinetics of lipopolysaccharide (LPS)-induced human monocytes activity in vitro. Cell. Immunol. 275, 55-60

66. Miller, M. J., Wei, S. H., Parker, I., and Cahalan, M. D. (2002) Twophoton imaging of lymphocyte motility and antigen response in intact lymph node. Science 296, 1869-1873

67. Nishibu, A., Ward, B. R., Jester, J. V., Ploegh, H. L., Boes, M., and Takashima, A. (2006) Behavioral responses of epidermal Langerhans cells in situ to local pathological stimuli. J. Invest. Dermatol. 126, 787-796

68. Zhang, H., Wang, L., Liu, S., Xie, Y., Deng, X., He, S., Zhang, J., Sun, S., $\mathrm{Li}, \mathrm{X}$., and Li, Z. (2013) Two-photon imaging of the cornea visualized in the living mouse using vital dyes. Invest. Ophthalmol. Vis. Sci. 54, $6526-6536$

69. Ueta, M., Koga, A., Kikuta, J., Yamada, K., Kojima, S., Shinomiya, K., Ishii, M., and Kinoshita, S. (2016) Intravital imaging of the cellular dynamics of LysM-positive cells in a murine corneal suture model. $\mathrm{Br}$. J. Ophthalmol. 100, 432-435

70. Kojima, S., Inoue, T., Kikuta, J., Furuya, M., Koga, A., Fujimoto, T., Ueta, M., Kinoshita, S., Ishii, M., and Tanihara, H. (2016) Visualization of intravital immune cell dynamics after conjunctival surgery using multiphoton microscopy. Invest. Ophthalmol. Vis. Sci. 57, 1207-1212

71. Lee, E. J., Rosenbaum, J. T., and Planck, S. R. (2010) Epifluorescence intravital microscopy of murine corneal dendritic cells. Invest. Ophthalmol. Vis. Sci. 51, 2101-2108 
72. Carlson, E. C., Drazba, J., Yang, X., and Perez, V. L. (2006) Visualization and characterization of inflammatory cell recruitment and migration through the corneal stroma in endotoxin-induced keratitis. Invest. Ophthalmol. Vis. Sci. 47, 241-248

73. Meek, K. M., and Fullwood, N. J. (2001) Corneal and scleral collagens-a microscopist's perspective. Micron 32, 261-272

74. Friedl, P., and Weigelin, B. (2008) Interstitial leukocyte migration and immune function. Nat. Immunol. 9, 960-969

75. Chieppa, M., Rescigno, M., Huang, A. Y., and Germain, R. N. (2006) Dynamic imaging of dendritic cell extension into the small bowel lumen in response to epithelial cell TLR engagement. J. Exp. Med. 203, 2841-2852

76. Ng, L. G., Hsu, A., Mandell, M. A., Roediger, B., Hoeller, C., Mrass, P., Iparraguirre, A., Cavanagh, L. L., Triccas, J. A., Beverley, S. M., Scott, P., and Weninger, W. (2008) Migratory dermal dendritic cells act as rapid sensors of protozoan parasites. PLoS Pathog. 4, e1000222

77. Cook, W. J., Kramer, M. F., Walker, R. M., Burwell, T. J., Holman, H. A., Coen, D. M., and Knipe, D. M. (2004) Persistent expression of chemokine and chemokine receptor RNAs at primary and latent sites of herpes simplex virus 1 infection. Virol. J. 1, 5

78. Yamagami, S., Miyazaki, D., Ono, S. J., and Dana, M. R. (1999) Differential chemokine gene expression in corneal transplant rejection. Invest. Ophthalmol. Vis. Sci. 40, 2892-2897

79. Gao, N., Lee, P., and Yu, F. S. (2016) Intraepithelial dendritic cells and sensory nerves are structurally associated and functional interdependent in the cornea. Sci. Rep. 6, 36414

80. Shortman, K., and Naik, S. H. (2007) Steady-state and inflammatory dendritic-cell development. Nat. Rev. Immunol. 7, 19-30
81. Guilliams, M., Ginhoux, F., Jakubzick, C., Naik, S. H., Onai, N., Schraml, B. U., Segura, E., Tussiwand, R., and Yona, S. (2014) Dendritic cells, monocytes and macrophages: a unified nomenclature based on ontogeny. Nat. Rev. Immunol. 14, 571-578

82. Blomster, L. V., Vukovic, J., Hendrickx, D. A., Jung, S., Harvey, A. R., Filgueira, L., and Ruitenberg, M. J. (2011) $\mathrm{CX}_{3} \mathrm{CR} 1$ deficiency exacerbates neuronal loss and impairs early regenerative responses in the target-ablated olfactory epithelium. Mol. Cell. Neurosci. 48, 236-245

83. Hashimoto, M., Yanagisawa, H., Minagawa, S., Sen, D., Ma, R., Murray, L. A., Tsui, P., Lou, J., Marks, J. D., Baron, J. L., Krummel, M. F., and Nishimura, S. L. (2015) TGF- $\beta$-dependent dendritic cell chemokinesis in murine models of airway disease. J. Immunol. 195, 1182-1190

84. Coppieters, K., Martinic, M. M., Kiosses, W. B., Amirian, N., and von Herrath, M. (2010) A novel technique for the in vivo imaging of autoimmune diabetes development in the pancreas by two-photon microscopy. PLoS One 5, e15732

85. Bousso, P., and Robey, E. (2003) Dynamics of CD8+ T cell priming by dendritic cells in intact lymph nodes. Nat. Immunol. 4, 579-585

86. Nguyen Hoang, A. T., Chen, P., Björnfot, S., Högstrand, K., Lock, J. G., Grandien, A., Coles, M., and Svensson, M. (2014) Technical advance: live-imaging analysis of human dendritic cell migrating behavior under the influence of immune-stimulating reagents in an organotypic model of lung. J. Leukoc. Biol. 96, 481-489

Received for publication April 10, 2018. Accepted for publication August 27, 2018. 